
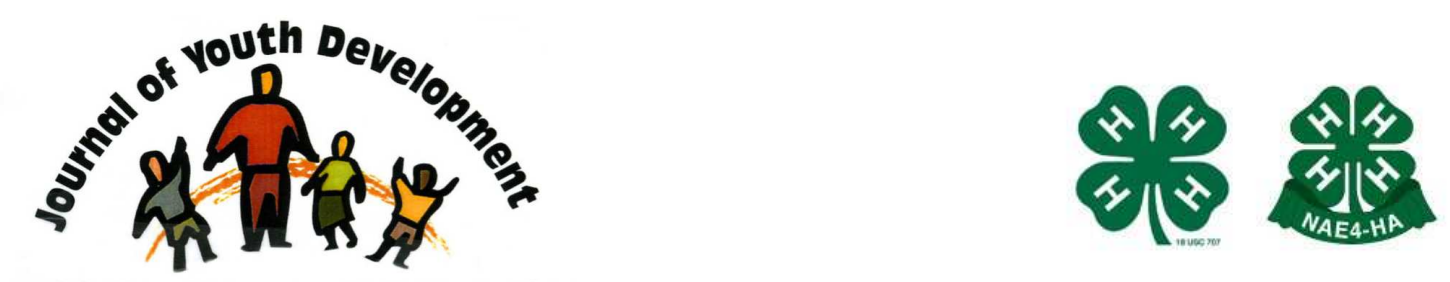

Bridging Research \& Practice

\title{
'A Good Friend': The Role of Peer Networks in Juvenile Treatment Courts
}

\author{
Pamela Linden \\ School of Social Welfare \\ Stony Brook University \\ Stony Brook, NY \\ plinden@notes.cc.sunysb.edu \\ Shelly Cohen \\ School of Social Welfare \\ Stony Brook University \\ Stony Brook, NY \\ scohen@notes.cc.sunysb.edu
}




\title{
JOURNAL OF YOUTH DEVELOPMENT \\ bridging research and practice

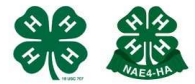

Volume 4, Number 1, Spring 2009

Article 090401FA004

\section{'A Good Friend': The Role of Peer Networks in Juvenile Treatment Courts}

\author{
Pamela Linden and Shelly Cohen \\ Stony Brook University
}

\begin{abstract}
A primary goal of Juvenile Treatment Courts is participant abstention from the use of alcohol and drugs. The present paper seeks to understand the role of social networks in participant abstention by examining the accounts of peer interactions of 37 current and former youth participants in New York State. This qualitative study found that while severing deviant network ties were involved in abstention in some cases, the dominant theme was the perceived protective role of emotionally close, albeit drug using, peers in supporting abstention. Although most cognitively based adolescent chemical abuse treatment programs explore the role of social networks in youth chemical use and abuse, the findings that youth in Juvenile Treatment Court programs have continued exposure to drugs and alcohol through interaction with their social networks suggest that social network interactions also enter into the discourse taking place within Juvenile Treatment Court settings.
\end{abstract}

\section{Background}

Interviewer: Was it hard for you to stop smoking weed?

Respondent: It was hard in the beginning because I would always be around it.

(Hope, Phase 2, PINS)

A common adage within the chemical abuse treatment field is that in order to achieve and maintain sobriety, an individual must "change people, places and things." That is, to avoid environmental cues that may initiate relapse. How does this adage apply to adolescents in Juvenile Treatment Court settings? Unlike adults who have the autonomy to change their living locations, jobs and communities, adolescents have little, if any, control over where they live and go to school.

Studies have consistently found that the delinquency of a person's friends is among the strongest correlates of his or her own delinquent behavior (Glueck \& Glueck, 1950; Haynie, 
2001; Warr,1996). Delinquent peers have been implicated in initial use of drugs in preteens, with curiosity, external influences and a desire to conform interacting in a complex dynamic (McIntosh, et al., 2003). Affiliation with deviant peers has also been shown to predict the development of substance use disorders (Moss, Lynch, \& Hardie, 2003).

Social pressure from peers, along with withdrawal and negative affect, has been found to play a role in relapse after treatment, with close to two thirds of adolescents relapsing within six months of discharge (Cornelius et al., 2007). In contrast, Bauman \& Ennett (1996) recommend a "more critical look at the power of peer influence" (p. 194), suggesting that peer influence plays a more limited role in adolescent drug use and that selection and influence make equal contributions to drug behavior homogeneity of peer groups.

During the transition into adolescence, adolescents spend increasing amounts of time alone and with friends, and there is a dramatic drop in time adolescents spend with their parents (Larson \& Richards, 1991). Adolescents choose friends with similar behaviors, attitudes, and identities (Akers, et al., 1998, Hogue \& Steinberg, 1995), and peers are considered to be among the strongest proximal influences of substance abuse (Fite, et al., 2006). The objective of this study was to understand the role of peer networks in the lives of Juvenile Treatment Court participants using a qualitative study design.

\section{Juvenile Treatment Court Programs}

Family Courts in New York State (NYS) handle a much younger population than most states. In NYS, the family court has jurisdiction over children under the age of sixteen who commit a crime and are adjudicated as a juvenile delinquent (JD). Offenders over the age of sixteen are deemed adults and are prosecuted in criminal courts. Persons in Need of Supervision (PINS) can be adjudicated in New York State up to the age of 18 for status offenses.

Juvenile Treatment Court (JTC) programs are specialized Family Court programs implemented by a cohesive team usually consisting of a judge, presentment attorney, law guardian, program coordinator, probation officer, education representative, and mental health/substance abuse treatment professional. Some programs include innovative corollary services designed to provide prosocial youth development, such as mentoring, or adventure-based programming.

In the initial phase of the program, youth usually make weekly appearances before the judge, are drug tested a minimum of once per week, have court-imposed early curfews and, in some court programs, house arrest with electronic monitoring. Strict monitoring is generally achieved through a probation officer's home and school visits. Most JTCs have a progressive three-phase structure - as youth meet program requirements, they regain freedoms in the form of reduced frequency of court appearances and drug tests, and later curfews. JTC programs require youth to abstain from drugs and alcohol, attend school, achieve passing grades and follow parents' rules at home.

JTC programs employ a schedule of graduated sanctions in response to non-compliance events, ranging from verbal admonishment from the judge to placement in detention centers. Although JTCs investigate, intervene and monitor the youth's major life domains such as school, home and treatment, most courts do not inquire about activities that youth engage in with their social networks. 
This study attempted to address one of the research questions posed in the article The Challenges of Conducting Research in Drug Treatment Court Settings (Belenko, 2002): "How does the role of peer influence on drug use and criminal behavior operate in a drug treatment court setting to reinforce abstinence?" Unlike the vast majority of research on JTCs which are quantitative and focus on outcome measures such as correlates of success and failure and participant recidivism, the overall aim of this study was to gain an in-depth understanding of the experience of being in a JTC program through the voices and perspectives of the youth themselves.

\section{Methods}

As part of a larger research project conducted to develop a JTC curriculum for NYS family court teams, interviews with 37 current and former adolescent participants within four JTC programs in NYS were completed over the course of two years (2004-2006). Participants were purposefully selected from various phases of court program participation. Each interview lasted between one and two hours. The majority of these interviews took place in private consultation rooms generally used by attorneys and clients in the courthouses. Participants were compensated with a $\$ 10.00$ gift certificate to a local discount store.

Subjects. Of the 37 current and former JTC participants interviewed, 18 were male and 19 were female. The youth ranged in age from $13-18$ years, with the mean age at time of interview being 16.1 ( \pm 1.2 ). Of the 37 interviewed youth, 24 were Caucasian and 13 were African-American. Ten were PINS, 22 were adjudicated as a JD and 5 were petitioned to appear before a judge for a low level offense (such as graffiti, fighting in school, vandalism). Program status at the time of the interview was 7 in Phase One, 13 in Phase Two, 5 in Phase Three, 7 Graduated, 1 Failed and 4 Active participants in a Juvenile Intervention Court which did not use a progressive phase structure. While the majority (32) were participants in court programs for which the specific target population was chemically dependent or abusing adolescents, 5 were affiliated with a Juvenile Intervention Court and did not have a substance use or abuse diagnosis.

Prior to participation in the study, written informed consent was obtained from parents/guardians, and assent was obtained from minor children. The study was approved by the Stony Brook University Committee on Research Involving Human Subjects. A Certificate of Confidentiality for the study was obtained from the National Institute of Drug Abuse (U.S. Department of Health and Human Services, 2007).

Semi-structured Interview. The 21-item semi-structured interview guide items explored youth major life domains, including home, school, court, social networks and treatment. The openended questions aimed at exploring the youth perception of the specialized court from several vantage points. Social networks were explored by asking youth to talk about friends- "Tell me about your friends." Probing questions and prompts clarified responses and generated new inquiries based on the youth narratives.

Qualitative analysis. Qualitative research methods are the most appropriate for understanding the quality and types of information regarding the subjects' worldview. This study utilized a modified grounded theory approach (Straus \& Corbin, 1998), which focuses on description and discovery, rather than theory testing or verifications (Hoshmand, 1989). Using qualitative methods of observation and interviews, data is presented in the context of participant's experience, adding richness and credibility to the results. Miles \& Huberman's (1994) analysis 
procedures, detailing analysis sequence from descriptive to inferential, were employed. First, initial descriptive codes were identified, then interpretive codes were applied based on identified patterns, and lastly, categories of patterns of descriptive codes were identified and are presented below.

\section{Results}

Several noteworthy themes regarding JTC participant peer group interactions emerged from the youth narratives, but the most prevalent theme was frequent community exposure to drugs and/or alcohol. For some abstaining youth, severing deviant network ties and establishing new, non-drug using peer groups supported abstention efforts. However, peer network abstinence reinforcement also emerged in the form of youth perceptions of protective functions of drug using peers. Youth described several types of social network relationships, from emotionally close friendships to superficial, acquaintance "clique" groups.

\section{Peer Influence: Exposure to drugs and alcohol}

All but 15 interviewed youth reported opportunities to use illegal drugs by spending time with drug using peers throughout their participation in the court program. When abstaining youth were asked if it was hard to maintain sobriety, many indicated that it was hard for them at first because they were frequently exposed to drugs and alcohol. As one youth said:

Interviewer: Was it hard being clean, getting clean?

Respondent: At first, just because all my friends were using.

(Briane, Graduate, JD)

Youth described peer groups that were non-homogeneous with regard to drug and alcohol use when they explained that they continue to maintain pre-treatment friendship networks with drug using peers. This reported abstinence in the face of frequent exposure to drug and alcohol use by friends suggests that youth select and maintain peer networks on the basis of other factors than solely shared drug and alcohol use.

Intuitively, the JTC setting would provide a ready-made sober support group for participants because they are all under the same court mandated expectation of abstinence. Seven interviewed youth provided unsolicited comments regarding other court program participants, indicating a suspiciousness of others' motivation to abstain from drugs and alcohol, commenting "Cause I like I know a lot of kids who just are in this just to get it over with," and "A lot of them there like pretend that they're gonna stop doing drugs and stuff like that and then they like really do coke like half the week and stuff like that." One participant spoke about others who cheat drug tests, saying:

There are a lot of people who are on drug court who cheat on their tests, who drink every night or something and just don't drink before they come to court or something...there's always going to be people who try and cheat the system and stuff.

(Kelvin, Phase 3, JD).

A female graduate reflected, "They were all still getting high. The kids that I knew that were in it, they were all still doing their thing, on the low." One youth, who graduated from the court program one week previous, shared his expectation that many youth graduating from the program go on to use drugs again. He said, "I guarantee you at least fifty percent of those kids [graduated] already used since a week ago...a kid right next to me was like 'yeah, I'm smoking tonight.' Right after he graduates, and I'm just like 'what an idiot'." Another youth, about to 
graduate and who had no violations throughout the court program, conspiratorially shared with the interviewer the secret to cheating drug tests, saying:

Honestly, I gotta tell the truth, alright? Going to court every three weeks, ok, you know a lot of kids could just smoke weed and come back clean. All they have to do its smoke as soon as they get out of court that night. They could probably do some the next day too and be able to come back dry as a bone."

(Sam, Phase 3, JD)

James, a JD who graduated from the court program one year previous to the interview, shared that he "made connections for drugs while I was in detention." After being clean for one year, he and another JTC youth participant relapsed. He explained:

Interviewer: So do you have a new group of friends that you hang out with now?

Respondent: Ah, not now. I don't really I mean I got a new group of friends but they're (laughing) also like the bad crowd and I ended up getting into more trouble after drug court... then started drinking again here and there with this one kid who was going to drug court and...we got into so many drugs and we came back and got into more trouble. ...I need to remember what I learned just stay away from the bad crowds and try and you know try and stand on your own two feet instead of relying on friends for a while and rely on family.

\section{Severing Ties with Drug Using Peer Network}

Of the 37 interviewed youth, 14 made the conscious decision to sever ties with drug using peers altogether, citing reasons including not wanting to get into any more trouble, not wanting to jeopardize their own recovery, and the conscious recognition of the destructive role peer drug use has on their own recovery. Some youth said that they "cut off whole groups of people" to reduce the temptation to relapse and others shared that they severed ties because they no longer wanted to belong to a deviant peer group.

Sandra, Phase 2, JD, agreed with her mother's sentiment that she "was with the wrong people." She said that although she still sees the people that she used to do drugs with, she doesn't spend time with them. Rather, she spends her time with non-drug using friends. She explained her decision to sever ties: "Well, it's just easy because, I don't know, I just don't want to do it no more - I don't want to get in trouble."

Another abstaining youth with concerns about getting into more trouble said:

I already had my strikes, I'm already in trouble. I can't afford to get in trouble again. I don't want to say you know the friends I chose to have are bad but you know everybody has you know knows somebody that's a little wild, you know...because the people you surround yourself by, you know, rub off on you so. Just stick to myself and if I do you know like I'll talk you know, I mean I do associate myself with them, but not like how I used to.

(Robert, Phase 2, JD)

One sober program graduate (Carlos, PINS), said, "I always had friends. I just hung out with the wrong crowd you know? Sooner or later you're going to start doing what they're doing. Just a matter of time." Another abstaining youth whose mother moved to a new community while she was in a substance abuse rehabilitation facility in an effort to support her daughter's recovery, expressed her fear of relapsing if she continued to interact with her pre-treatment social network. She said: 
Like it's really hard to make new friends and stuff but it was good because it got me away from people that I got in trouble with, because I know if I was back home hanging out with the old people, I'd probably get talked into going shoplifting or drink or something like that.

(Debra, Phase 2, PINS)

Abstaining youth who severed ties with pre-treatment peer groups described them as "using me for drugs," and described those relationships as "acquaintances" rather than "friends." These relationships were not based on mutual caring. Youth said that those friends "don't care" if they do drugs or not. Another youth (Mark, Phase 1, JD) who only had four weeks clean after being in the program for one year, said that his friends are "more like acquaintances." When asked what he thought he needed to do to stay clean, one youth struggling with sobriety recognized that he needed to sever ties with delinquent peers who he believed did not have his best interests in mind. He explained:

Respondent: Stay away from my friends no matter how much you know I want to hang out with them or talk to them or whatever. If I need friends here I got to find new ones. I can't be hanging out with the same people or else I'm going to be dragged back in.

Interviewer: Do the friends that you hang out with now, do they know you are trying to stay clean?

Respondent: Yeah.

Interviewer: Do they care? I mean, do they still smoke in front of you?

Respondent: Well, I don't go around them anymore. They would be, they would be smoking in front of me.

Interviewer: They would smoke in front of you.

Respondent: Yeah. So, they're not really friends.

(Frankie, Phase 2, PINS)

\section{Selecting New Peer Group}

Nine of the interviewed youth severed ties with their former drug using peer networks and established new non-drug using friendships. Two youth found satisfying new peer relationships with individuals they met through AA and NA meetings. One youth explained:

Interviewer: Now the people that you started using with, are you still friends with that crowd?

Respondent: No. I'm not friends with any of them...they really never even called me like when I went to rehab, you know? They really weren't real friends. They were just kids I got high with. You know and most of them now are doing cocaine you know they're not smoking pot anymore. And that probably would have been me if I kept going down that road...I have a lot of friends from the meetings...It's awesome. We go out to dinner, go out to eat you know my friend [from the meetings] has a Mustang...We have fun in it. (Carlos, Graduate, PINS)

One youth explained her expectation that her new peer group would disapprove of her using drugs. Implicit in her statement was the belief that her new friends would have her best interest in mind. She said:

So I don't hang out with people that I know are going to influence me in a bad way. I mean any of my friends, if they even found out that I smoked weed right now they wouldn't even talk to me. Cuz they know what kind of situation I'm in. (Sally, Phase 2, PINS) 
Several youth expressed direct assertiveness when confronted with peers offering them drugs or alcohol. One youth told peers, "No, man, I don't do that shit." Another youth described assertiveness by making sure that "When I want to date a guy I make sure they're not doing drugs. I don't care if it's smoking weed or drinking everyday." Many described finding new nondrug using friendship networks in which they spend time doing enjoyable non-drug using activities.

\section{Nature of Peer Relationships}

While those abstaining youth who severed prior relationships described these as superficial acquaintances based on mutual drug and alcohol use, youth who made the conscious decision to maintain pre-treatment social networks described those relationships as "tight," "caring," and "best friends." One youth in Phase Two of the court program said that it's "a little bit hard" for him to stay clean. He shares that he got into legal trouble when he and his friend were caught with a large amount of marijuana and a scale. He differentiates between close friends and acquaintances, saying:

Interviewer: Are you still friends with folks you hung out with at that time or no? Respondent: Yeah. They tell me I'm not supposed to, but those are my friends. I only got like two good friends I consider, or everybody else I don't care about. ...And then, then a lot of people that I hang out with. I know, I know a lot of people. I don't consider them friends.

(Rick, Phase 2, JD)

Other youth described protective emotionally close dyads, such as a romantic partner or "best friend" who does not use drugs or alcohol, as integral to the maintenance of their sobriety. I had more groups of friends than pretty much anybody I know. I hung out with this group, I hung out with that group, and I hung out with every group of people. So I just stopped that. Pretty much the only people I hang out with is my girlfriend and my best friend that lives next door. We have been friends since we were kids little kids. We lived next door to each other my whole life and his whole life.

(Matt, Phase 3, JD)

One youth explained that her best friend warns her not to use drugs or alcohol, saying: My best friend...she doesn't do drugs and before she used to be like "You're gonna go to jail, get sent away again." Like she's always been there like she's a big sister kinda like, looking out for me. So and like a few weeks ago we were watching a football game at her friends house and everybody was around us smoking weed and stuff, and [she] doesn't smoke weed and she was like " you guys, can you guys go smoke weed in the next room so we can watch the game, You know?" she's like " [She] doesn't want to be around this, I don't want to be around this" so then they... like she's looking out for me all the time. She's a good friend. (Briane, Graduate, JD)

\section{Retaining Drug Using Acquaintance Groups}

Five youth stated that although it was recommended that they change their friends, they made the decision to retain those friendships, believing that their peer networks were 'protective' of them. One youth who graduated from the court program said: 
Interviewer: Was it hard being clean, getting clean?

Respondent: At first, just because all my friends were using and I refused, I totally refused to change my friends. But the whole time, the whole time I was clean, it was hard at first but after like about the first month I was fine. I didn't care...cause like in treatment they try, they suggest you change like the places you go to and you change your friends and all that but I wouldn't change my friends because I didn't feel like I should have to you know I didn't want to change everything. I changed parts of my lifestyle like my behavior but I just I couldn't leave my friends cause they're a part of the reason, you know people who were helping me. Yes, they were using but like they would go into a different room or they would like, they were proud of me I could tell they were proud of me even though they were still using.

(Briane, Graduate, JD)

Youth believe that their drug using friends supported their efforts toward sobriety and engaged in physical, cognitive and emotional 'protections.' Youth understood peer behaviors as protective when friends announced their intention to use drugs, thus giving the youth a warning and the opportunity to remove themselves and by stating their intention to leave the area themselves to use drugs with the expectation that they youth would not join them. Some youth expressed the expectation that 'protective' friends would verbally warn them not to use drugs and remind them of the severe consequences they would receive as a JTC program participant. One youth shared:

Most of them, mostly everybody I hang with now, they all know, like they be telling me, like before when I was like lying and smoking and stuff, they was telling me like, 'Man you gonna get in trouble, you better stop.' Then like the people I hang with now but like the people that was smoking with me while I was on probation I don't hang with them no more because they knew I was on probation but they were still you know [smoking with me].

(Mike, Phase 3, JD)

Some youth felt supported in their sobriety maintenance by drug using friends. One youth explained:

They'd [friends] like brag to other people how long I'd been clean for and that kind of stuff and so like they made me feel good and so I was like you know I can handle it and its like if they were around and we were in a car or something like that and they were like driving and wanted to smoke I could be just like no and they wouldn't so they totally respected how I felt.

(Briane, Graduate, JD)

Charlie, a JD who failed out of the program two years previous to the interview and has since maintained two years of sobriety described stopping by the park to say hello to long-time drug using friends "like cause we all, all grew up friends, we best friends, like we all grew up together." He reported that when his friends go to smoke marijuana, they let him know first. When asked if his friends know that he's being trying to get clean, he said:

They used to like, have like help me strive for... Like when they smoke they'd be like, 'we about to go outside and smoke' they'll leave or something like that, like 'we going around the corner to go smoke' and I be like all right...when I be like I wanna come with them. They be like nah man... [my parents] thinks that my friends like pulling me into doing negative stuff. And they're not. They like, they keep me out of most of this stuff that I should be getting in trouble for. 
Another youth, still in the first phase of the court program and with only four weeks clean time, described his perspective that drugs aren't all that bad. He described the quality of his relationship with his drug using social network as "hanging out" rather than in terms of emotional friendship bonds. When asked if it bothers him that his friends continued to use drugs around him, he said:

Respondent: It's no big deal to get high really, it's just not what everybody thinks it is, (who) That doesn't really do it, its just it's just something to make you feel better it's not like you don't even know what the hell you're doing. Its just you do it cause it makes you feel better. It's just what it does, I don't know. Interviewer: So does it bother you at all that they use when you are trying to stay clean?

Respondent: They're doing their thing and I'm doing my thing, you know? So Interviewer: Do you feel like your friends care about you, are they close friendships or Respondent: No. No, they're just, hanging out (Mark, Phase 1, JD)

Ryan, a JD in Phase 3, said that it does not bother him anymore when his friends use drugs around him. He believed that his friends do not intend to pressure him into using drugs and respect his wishes when he declines the offer to use drugs with them. He said:

You know like they knew that I was on probation and stuff like that and you know, they might ask like in the beginning they'd ask me if I want some and if I told them nah I can't then they wouldn't ask me again, you know, they.. I told them it didn't... it doesn't bother me anymore for them to smoke in front of me like, I can smell it now and it really doesn't make me want to smoke at all like I can sit there and watch them it doesn't do anything to me. So, just, if I tell them I don't wanna smoke they understand and they don't wanna they don't pressure me into it.

\section{Discussion}

Research on normal adolescent development suggests that primary groups shift during adolescence from family and parents to peer networks (Fuligni \& Eccles, 1993). The development of a separate identity is a major task while youth are going through this normal developmental process. They still want to be seen as "normal" by going to parties and socializing with peers. Nevertheless, while strictly monitoring youth behavior in the major life domains of home, school, treatment and community supervision, most JTC's do not explore with youth their thoughts about their social networks.

The finding that nearly half of interviewed youth reported being exposed to drug use by their social networks while in the JTC program should be a concern to courts. Although courts emphasize the roles of parents and families in youth rehabilitation, these data show that social networks play a major role in youth initial substance use, continued use and relapse episodes.

Youth interviews suggest that friendship networks can be understood to be risk factors for relapse and continued delinquency or protective, depending upon the degree of emotional closeness that the individual experiences in these relationships. Courts should consider conducting a social network analysis with youth upon entering the court program and routinely 
ask youth who they are spending time with. Court programs can use the leverage of the courts to link youth with opportunities for prosocial development.

\section{Policy Implication}

JTC's emphasize parent involvement in the lives of youth. Our findings support previous research demonstrating the developmental importance of social networks in the lives of youth. It may be beneficial to youth and families if JTC professionals incorporate inquiries regarding friendship networks as part of the routine intake protocol and make frequent periodic inquiries, such as during regular court appearances, about who is in their friendship network and what type of activities they engage in with friends. Simply asking the question may serve to stimulate youth to reconsider what they are doing and with whom.

Some JTC's have formed partnerships with youth development organizations such as mentoring and therapeutic recreational activities in addition to mandated chemical abuse treatment services. Courts should increase efforts to expose youth to pro-social youth development opportunities to increase the likelihood of achieving juvenile justice goals.

\section{Limitations to the Study}

There are several limitations to the research design that should be noted when interpreting the present findings. First, given the qualitative methodology utilized, the sample was not intended to be random and the results are not intended to be generalized. The study was limited to four operational JTC's in NYS. In addition, interviews included only one youth who had failed out of the JTC program. Due to time and resource limitations, a follow up study of youth outcomes could not be conducted. Further studies are warranted to reveal the longer term differential effects of diverse peer group affiliation for adolescents in recovery and involved in the juvenile justice system.

\section{Acknowledgements:}

The authors wish to express their appreciation to the New York State Unified Court System, Division of Grants and Program Development, especially Michael Magnani, Ann Bader and Robyn Cohen, for their assistance in implementing this project. We also appreciate the cooperation of the four Juvenile Treatment Court programs for providing access to youth as well as space to conduct this study. In addition, the author's extend our appreciation to the youth and their families who consented to participate in this study.

Author's Note:

This research is supported under Award 2003-DC-BX-0052 from the Bureau of Justice Assistance, Office of Justice Programs, U.S. Department of Justice. The opinions and interpretations expressed in this article are those of the authors and do not necessarily represent the official position of the U.S. Department of Justice or the New York State Unified Court System.

\section{References}

Akers, J., Jones, R., \& Coyl, D. (1998). Adolescent friendship pairs: similarities in identity status development, behaviors, attitudes, and intentions. Journal of Adolescent Research, 13, 178-201.

Bauman, K., \& Ennett, S. (1996). On the importance of peer influence for adolescent drug use: commonly neglected considerations, Addiction, 91,(2), 185-198. 
Belenko, S. (2002). The challenges of conducting research in drug treatment court settings, Substance Use \& Misuse, 37, 12 - 13, 1635-1664.

Cornelius, J., Clark, D., Reynolds, M., \& Kirisci, L. (2007). Early age of first sexual intercourse and affiliation with deviant peers predict development of SUD: A prospective longitudinal study. Addictive Behaviors, 32, (4). 850-854.

Fite, C., \& O'Connor, R. (2006). Childhood behavior problems and peer selection and socialization: Risk for adolescent alcohol use, Addictive Behaviors, 31, 1454-1459.

Fuligni, A., \& Eccles, J. (1993). Perceived parent-child relationships and early adolescents' orientation toward peers. Developmental Psychology, 29, 4, 622-632.

Glueck, S., \& Glueck, E. (1950). Unraveling Juvenile Delinquency. Harvard University Press.

Haynie, D. (2001). Delinquent Peers Revisited: Does network structure matter? American Journal of Sociology, 106, 1013 - 1057.

Hogue A., \& Steinberg, L. (1995). Homophily of internalized distress in adolescent peer groups, Developmental Psychology, 31, 897-906.

Hoshmand, L.T. (1989). Alternative research paradigms: A review and teaching proposal. The Counseling Psychologist, 17, 3-79.

Larson, R., \& Richards, M. (1991). Daily companionship in late childhood and early adolescence: changing developmental contexts, Child Development, 62, 284-300.

McIntosh, J., MacDonald, F., \& McKeganey, N. (2003). The initial use of drugs in a sample of pre-teenage schoolchildren: the role of choice, pressure and influence. Drugs: education, prevention and policy, 10, 2, 147-158.

Miles, M., \& Huberman, A. (1994). Qualitative data analysis: An expanded sourcebook. Thousand Oaks, CA: Sage.

Moss, H., Lynch, K., \& Hardie, T. (2003). Affiliation with deviant peers among children of substance dependent fathers from pre-adolescence into adolescence: associations with problem behaviors. Drug and Alcohol Dependence, 71, 2, 117-125.

Straus, A., \& Corbin, J. (1998). Basics of qualitative research: Techniques and procedures for developing grounded theory. Thousand Oaks, CA: Sage.

Warr, M. (1996). Organization and instigation in delinquent groups. Criminology, 34, 11-38.

(c) Copyright of Journal of Youth Development Bridging Research and Practice. Content may not be copied or emailed to multiple sites or posted to a listserv without copyright holder's express written permission. However, users may print, download or email articles for individual use. 